\title{
Un especial supuesto de contrato entre Entes públicos
}

\author{
por \\ FRANCISCO J. LLISET BORRELL
}

Sumario: I. Colaboración y coordinación administrativa.-II. Los planes provinciales de inversión.-III. Naturaleza de los contratos celebrados entre la Comisión provincial de Servicios técnicos y el Municipio: su repercusión en la aplicación del Impuesto de Derechos reales.

I. Reviste especial interés, por los problemas que en la práctica suele plantear, el fenómeno de la actuación simultánea y coordinada de la Administración general, la intermedia y la municipal, frente al criterio de la competencia exclusiva de cada una de ellas.

La doctrina se ha percatado bien pronto de la importancia de tal fenómeno, siendo, incluso, considerado como una de las tendencias actuales del régimen local (1). Ya en 1944 el profesor Ruiz del Castillo; escribía: “Ni el Estado puede vivir ausente de la vida local, ni prescindir de la colaboración de las Entidades locales cuando trata de cumplir sus propios fines. Inversamente, esta colaboración de las Entidades locales concentra en ellas una mayor suma de poder efectivo. Hoy resulta artificial y opuesto a las exigencias vitales, delimitar rígidamente las esferas de competencias, según el esquema tradicional: Estado, Provincia, Mu-

(1) JORDANA DE POZAS: Tíndencias europeas actuaies del Régimen local, dis. curso leído en la Real Academia de Jurisprudencia y Legislación el 19 de enero de 1948. 
nicipio...n (2). Con posterioridad han señalado esta tendencia Jordana de Pozas (3), Entrena Cuesta (4) y García Trevijano (5).

Aparte de la colaboración entre órganos de un mismo ente; materia propia del principio organizativo de coordinación (6), y de la colaboración entre entes locales de un mismo orden (7), y aún de distinto orden (8), una teoría general de la colaboración entre el. Estado y las Entidades locales debería comprender estas dos partes:

A) Colaboración de los entes locales a servicios estatales. Podríamos estudiar aquí el tema genérico de los servicios delegados (9), y algunos otros supuestos de interés como ias escueJảs, que tan rica gama de problemas plantean. No obstante, hay. que reconocer una corriente restrictiva en este aspecto a partir de la Ley de 3 de diciembre de 1953 y el Decreto de 18 de diciembre de 1953. Esta corriente de desgravación municipal de cargas estatales ha afectado al sostenimiento de Juzgados, casahabitación para maestros, etc.

B) Colaboración estatal a los entes locales. En este apartado, todavía cabría hacer la siguiente subdivisión :

(2) RU12 DEL CASTiLlo: Estructura y función de las Entidades locales, en -Revista de Estudios Po:íticosø, núm. 16, 1944.

(3). Op. cit.

(4) Consideraciones sobre la teoria general de los contratos de la Administración, Revista de Administración Públicas, núm. 24.

(5) Titularidad y afectación demanial en el Ordenamiento juridico español. Revista de Administración Públicas, núm. 29. Con anterioridad, en Relación org nica y de servicio en los funcionarios públicos, aRevista de Administración Públicas, número 13.

(6) Ortiz Dín: El principio de coordinación en la organización adminis. trativa, Instituto arcia Oviedos, Sevilla, 1956.

(7) García Trevijano: Op. cit., en primer lugar y Segismundo Royo V1LLANOVA, Los términos municipales y sus alteraciones, Instituto de Estudios de Administración Local, Madrid, 1947.

(8) En el texto aludimos, preferentemente, a los planes de cooperación provincial a los servicios municipales.

(9). Vid.: Un estudio de los servicios delegados ien Borsi, en el Primo Trattato de OrLando, sobre las funciones del Municipio italiano, desde el punto de vista sociológico Desde un punto de vista formal, ZanobINI, en L'Amministrasione locale, tercera edición, 1936. 
a) Supuestos de tutela administrativa, strictu sensu (10).

b) Supuestos de vigilancia de los entes locales por la Administración central.(11).

c) Supuestos de control a que dan lugar las subvenciones administrativas (12).

II. El último grupo de supuestos, esto es, el de las subvenciones, tiene en los momentos actuales una trascendencia que nadie le regatea. De una parte, García de Enterría (13) ha llegado a afirmar que las subvenciones son uun instrumento capital en la obra de conformación social en que la Administración de nuestros dias se halla rigurosamente comprometida...). Y de otra, con un efecto más directo sobre el tema que tratamos, Entrena Cuesta (14) nos dice que "parece lógico que si un servicio ha dejado de ser exclusivamente local (15), por lo que tampoco tienen este carácter los fondos con que se atienden, participen en el mismo los órganos de la Administración central, aunque sea limitándose a exigir que se presten de la forma que exijan las necesidades que con él se atienden".

Hechas las consideraciones que anteceden, debemos centrar el tema en el estudio de un caso particular de subvención que, ofre-

(10) Vid.: Para un estudio de la tutela, Garrido Falla: Administración indirecta del Estado y descentralización funcional, Instituto de Estudios de Administración ILocal, pág. 176 y siguientes. También ENTrena Cuesta: Los movimientos centralizadores en In glaterra, Instituto de Estudios de Administración Local, 1960, pág. 123 y sigs.

(11) ILa vigilancia constituye, mejor que la tutela, una auténtica colaboración estatal a los entes locales, porque no atiende tanto a la protección del interés general, cuanto a la protección de los intereses de los entes locales mismos.

(12) Un estudio bastante completo de las subvenciones administrativas en Viliar Palasf́, Las técnicas administrativas de fomento $y$ de apoyo al precio politico, en eRevista de Administración Públican, núm. 14. También en Garrido Falla: I'ratado de Derecho administrativo, volumen segundo, pág. 296. Sobre el control a que nos referimos en el texto, vid. Entrena Cuesta, op. cit., pág. 140 y Garrido Falla, op. cit., pág. 304.

(13). García de ENTERRfa: Sobre la naturalesa de las tasas y las tarifas de los servicios públicos, en aRevista de Administración Púbicas, núm. 12.

(14) Los movimientos centralizadores en Inglaterra, cit.

(15) Op. cit. pág. 151. 
cido por nuestra legislación más reciente, muestra una verdadera vis atractiva respecto de cualquier tipo de subvenciones y. ayudas para realizar obras de carácter local o provincial (16). Se trata de los plane:s provinciales de inversión que se llevan a cabo a través de un órgano estatal, las llamadas Comisiones provinciales de Servicios técnicos (17).

Las obras y los servicios que se lleven a cabo por este procedimiento subvencional ¿pierden por este simple hecho el carácter de municipales o provinciales?

A Entrena Cuesta (18) le parece lógico que, en estos casos, el servicio deje de ser exclusivamente local. También García Trevijano se orienta en este sentido hablándonos de una cotitularidad (19), aunque reconoce que la titularidad viene a consolidarse en el Municipio beneficiario. De este modo, afirma: "La tutela por estas ayudas económicas no puede ser perpetua». Esto es claro, puesto que una vez garantizado cumplidamente el destino de la suma de dinero en que la subvención consiste ya no hay razón para continuar fiscalizando, sin perjuicio de la tutela general que al Estado incumbe sobre las Entidades locales, como órganos indirectos que son de la Administración central, o al menos, como personas jurídicas integradas en la organización estatal (20).

III. 1. Pese a que las Comisiones provinciales de Servicios técnicos carecen de personalidad reconocida expresamente, parece como si, incluso, como señala Garcia Trevijano (21), sè pretendiese personificar estos organismos al encomendarse la realización directa de las obras o servicios aprobados, y su contratación por consiguiente.

(16) ORTIz DíAz: Unidad y coordinación de los órganos y servicios estatales a nivel provincial: El Decreto de 10. de octubre de 1958, REvista DE ESTUdios DE LA VIDA LOCAL, núm. 106.

(17) Op. cit., pág. 484

(18) Los movimienios centralizadores..., misma página.

(19) Ọp. cit., pág. 30.

(20) Garrido Falla: Administración indirecta..., pág. 114 y Tratad de de DeFecho administrativo, volumeñ primero, pág. 297.

(21) Titularidad y afectación demanial..., pág. 39. 
A estas Comisiones, verdaderos órganos de la Administración del Estado, incumbe la administración de los fondos asignados al aprobarse cada plan provincial. Para ello, como dejamos dicho, pueden celebrar, por sí mismas; contratos con arreglo al capítulo $\mathrm{V}$ de la Ley de Administración y Contabilidad del Estado, en su nueva redacción dada por Ley de 20 de diciembre de 1952. Aunque, a veces, por su importancia técnica o económica, se celebren por los Departamento ministeriales -Orden de 29 de marzo de 1958-, y otras por las propias Corporaciones - Orden de 21 de julio de 1958 .

2. De todos estos contratos, nos interesan tan sólo los que celebran las Comisiones provinciales de Servicios técnicos, que, por otra parte, constituyen la norma general. Estos cóntratos se rigen, según dijimos, por las normas de la contratación central, pudiendo ser contratista, a tenor del artículo 48 de la Ley de Administración y Contabilidad del Estado, las personas juridicas que se hallan en plena posesión de la capacidad jurídica y de obrar, sin perjuicio de las excepciones que se consignan en la misma Ley o en otras disposiciones.

Si el artículo $\mathbf{6}$ de la Ley de Régimen local declara la plena capacidad jurídica de las Corporaciones locales, enumerando, por otra parte, la facultad de celebrar contratos, no cabe duda de que los Municipios pueden ligarse contractualmente con las expresadas Comisiones provinciales para la realización de las obras y servicios municipales, subvencionadas por el Estado por el sistema de los planes provinciales de inversión.

3. Pero ¿cuál es la naturaleza de estos contratos? ¿ Se trata de un contrato de obras públicas o, por el contrario, de un contrato de naturaleza especial? Podemos señalar dos posturas extremas.

A) La prímera es mantenida por la mayoria de las Abogacias del Estado y los Tribunales Económico-administrativos provinciales.

A fin de que los citados contratos puedan ser objeto de liquidación por el Impuesto de Derechos reales, lo normal es que las Abogacias del Estado los consideren como contratos mix- 
tos de cbras con suministro. $Y$ no cabe duda que estos contratos, de acuerdo con los artículos 16, 18 y 25 del vigente Reglamento del Impuesto de Derechos reales, implican necesariamente, como reconoce el segundo considerando de la Resolución del Tribunal Económico-administrativo central de 12 de abril de 1960, el que una persona ejecute para otra, mediante precio, cierto servicio u obra, creando, modificando o transformando bienes propios del que pague el precio, con aportación o no de los materiales necesarios. De lo que resulta que los que mantienen esta postura defienden la calificación para los contratos que estudiamos de contratos de obras públicas, ya que éstos no suponen otra cosa, como reconoce Garrido Falla (22), que la aplicación a las obras públicas de los contratos de ejecución de obra por ajuste o precio alzado a que se refiere el artículo 1.588 del Código civil, cuyos elementos aparecen, por otra parte, traducidos en los artículos citados del Reglamento del Impuesto de Derechos reales.

B) La anterior posición no puede en absoluto mantenerse. Aparte de su simplicidad, es una consecuencia de las interferencias e implicaciones entre las técnicas empleadas por la Administración de nuestros dias, que producen no poca confusión y que obligan a inventar nuevas figuras jurídicas que recojan y comprendan la realidad multiforme, cada día más compleja.

Apenas entramos en el estudio de los elementos del llamado contrato de empresa -o arrendamiento de obras por ajuste o precio alzado-, se echa de ver el fallo de la calificación de las Abogacias del Estado. En efecto, Castán (23), al analizar los elementes personales de este contrato, nos dice: "Intervienen, de una parte, el que se compromete a realizar la obra (arrendador, contratista. o empresario), y de otra, aquel en cuyo provecho la obra se realiza (arrendatario, dueño de la obra o comitenten. Cierto que la Comisión provincial de Servicios técnicos adjudica la ejecución de la obra a los $\mathrm{Mu}$ nicipios interesados, en virtud de un contrato, según hemos

(22) Tratodo' de Derecho administrativo, pág. ' 62.

(23) Derecho civil español, comain y foral, pág. 468. séptima edición, 1952. 
dicho, pero en modo alguno puede darse en el caso que nos ocupa aquella distinción subjetiva entre empresario y propietario. Una y otra calidad coinciden en la misma persona: el Municipio. El Municipio realiza la obra en su propio provecho, aunque ayudado por el Estado mediante una subvención.

Pero éste es sólo el lado negativo de la cuestión. Lo que verdaderamente interesa es señalar no tanto que los contratos que enjuiciamos no son contratos de obras públicas, sino en qué categoría contractual cabe incluirlos. Para ello, conviene hacer algunas precisiones.

a) Se nos pucde objetar que resultará absurdo que se atribuya al contrato una naturaleza cuando se adjudique a un particular (contrato de obras públicas), y otra, cuando se adjudique a la Corporación local interesada. Pero lo verdaderamente anómalo es que la Comisión provincial sea titular de una competencia típicamente municipal: la celebración de contratos para la ejecución de obras y servicios municipales. No obstante, esta competencia que ha hecho hablar a García de Enterría de una personificación de la Comisión provincial de Servicios técnicos no minimiza ni enturbia la competencia municipal respecto de las obras y servicios municipales enumerados en el artículo 101 de la Ley de Régimen local, máxime teniendo en cuenta la posibilidad que establece la Orden de 21 de julio de 1958 de celebración de contratos sobre dichas obras por parte de las propias Corporaciones locales.

Claro que puede argüirsenos que no es auténtica muchas veces la competencia que enumera el artículo 101 de la Ley de Régimen local (24), pero, a nuestro juicio, es muy distinto el caso del gas, electricidad, transportes, etc., que son servicios concretos, centralizados por razón de la materia, y el de las obras y servicios municipales contemplados in genere, que pueden ser

(24) Garcfa de Enterrfa en El servicio público de los transportes urbanos, Revista de Administración Pública», núm. 10, pág. 53, 1953, y en ‘El se:vicio público de gas», conferencia inc'uida en su libro Problemas actuales de Régimen local, pág. 41. También Cravero Arévalo en el Prólogo a la:obra. El Reglamento de servicios de las Corporaciones locales, de Luis Marqús CARBó. 
objeto de los planes provinciales de inversión. Siguiendo el criterio gue atacamos, ocurriría que una misma obra o servicio, sin que existiese ninguna justificación sustancial, unas veces sería competencia de la. Comisión provincial de Servicios técnicos, y otras de las Corporaciones locales.

$\therefore$ Pero si la competencia, como decimos, continúa siendo muricipal ¿qué significa que sea la Comisión provincial de Servicios técnicos el órgano que saque a subasta las obras? Ello no es más que un control, consecuencia del otorgamiento por el Estado de la subvención. Sería absurdo, en el caso en que el contratista fuese un particular que, aparte del control evidente del que paga -el Estado-, existiese el propio del que celebra el contrato -el Ayuntamiento-. Por ésto, los controles se unifican en un solo órgano. En el supuesto que sea la propia Corporación local la que ejecute las obras, lo único que hace la Comisión de Servicios técnicos es conservar el control del empleo de la subvención, pero no conserva el control propio del propietario sobre el empresario, precisamente por que no hay tal empresario:

b) Dijimos más arriba, que las Corporaciones locales pueden, de acuerdo con las normas que regulan la contratación estatal, celebrar contratos. Pero ello requiere mayor aclaración porque las obras que tienen que realizar no son estatales, sino locales. Nos parece, por ello, que un planteamiento adecuado de la cuestión fuerza a contemplarla bajo una perspectiva local; à la luz de la legislación local. Por tanto si, en principio, como dejamos adelantado, no existe ningún obstáculo que nos impida admitir que la Comisión provincial de Servicios técnicos se encuentre ligada con los Municipios, con ocasión de los planes provinciales de inversión, mediante vínculos contractuales, habrá supuestos en que se dará aparentemente una imposibilidad. En rigor, serían éstos todos los pensables, excepto aquellos en que la Ley de Régimen local (25) permite la ejecución directa. No obstante, desde un punto de vista práctico; no hay ninguna ra-

(25) Art. 311 de la'Il.ey de Régimen loca?. 
zón que obligue a aplicar tan escrupulosamente el clásico principio del contratista interpuesto - que excluye a todas las personàs juridico-públicas de los contratos de obras públicas como contratistas-, sobre todo teniendo en cuenta, como ocurre en nuestro caso con las Corporaciones locales, que los entes públicos pueden actuar debidamente fiscalizados por órganos de una entidad superior que las comprenda. A esta finalidad atiende, precisamente, la institución de la tutela administrativa (26).

c) Atendiendo a una consideración independiente y microscópica de los diversos actos administrativos que se dan en nuestra hipótesis, tendremos:

1. Hor el Ayuntamiento se solicita la inclusión de un proyecto en el plan provincial de inversiones para obras y servicios.

2. Asignación de la subvención estatal, atendido el coste de la obra, consistente en una cantidad proporcional al presupuesto de la misma, siendo satisfecha la cantidad restante, hasta cubrir el coste total del proyecto, por el Ayuntamiento respectivo.

3. La Comisión provincial de Servicios técnicos, efectuada la aportación municipal, saca a subasta la ejecución de las obras o servicios, siendo adjudicada, en definitiva, en ocasiones, al propio Ayuntamiento titular.

Los dos primeros apartados configuran el medio de fomento que llamamos subvención, sin que nos importe ahora analizar su naturaleza jurídica. El apartado tercero alude a un mecanismo contractual, ya que, en virtud del acto de adjudicación, el Ayuntamiento se compromete a ejecutar las obras y la Comisión provincial de Servicios técnicos a pagar las certificaciones correspondientes.

C) Hechas las consideraciones que anteceden, debemos sentar unas conclusiones sobre la naturaleza de los contratos entre entes públicos que venimos estudiando, apoyándonos para ello en la Sentencia dictada por la Sala de lo Contencioso-administrativo de la Audiencia Territorial de Barcelona a 9 de junio de

(26) Nos remitimos a la bibliografia citada en la nota 10 . 
1961, cuya tesis tuvimos el honor de defender en la demanda que dio lugar a dicha sentencia.

a) Hemos adelantado que aunque formalmente ofrecen estos contratos la apariencia del tipo llamado "de obras públicas", sustancialmente están muy lejos de él. La citada Sentencia, en su segundo considerando, nos dice: "Que la figura del contrato de ejecución de obras, se da, en la ejecución de obras públicas, cuando la Administración, a través de las fórmulas jurídicoadministrativas de la subasta, el concurso o el concierto, elige un contratista y formaliza con él el contrato de ejecución, pero no existe el indicado negocio contractual cuando la Administración ejecuta la obra, sin la figura interpuesta del contratistan. Abundando en el mismo criterio, en el antepenúltimo considerando, de una forma mucho más explícita, manifiesta: "Que, en consecuencia, al concurrir el Ayuntamiento recurrente a la subasta convocada por la Comisión provincial de Servicios técnicos de Lérida $\mathrm{y}$, obtener, en régimen de contrato, la ejecución de las obras, se encubró, propiamente, un sistema de ejecución directta». Además, reiteradamente, llama al Ayuntamiento titular de la obra y beneficiario de la misma, confusión incompatible con la esencia del contrato de obras públicas, que exige la presencia de dos jersonas distintas con peculiares derechos y obligaciones derivados de la titularidad de la obra y de la construcción de la misma mediante un precio. El Abogado del Estado mantuvo que el Ayuntamiento obtenía un beneficio industrial, como cualquier contratista particular, fero la Sala consideró que itanto provoque un beneficio económico de la Administración, como una disminución de sus ingresos", al no existir tráfico patrimonial, no puede justificarse la exigibilidad del Impuesto de Derechos reales.

b) Hemos adelantado también el papel que, a nuestro juicio, juega, en estos contratos, la Comisión provincial de Servicios técnicos. Creemos, repetimos, que se trata, en este caso, de un órgano tutor (27): Viene ahora a cuento el tema de los

(27) Está por hacer un: estudio de los diferentes órganos estatales que ejercen una actividad tutelar sobre las Entidades locales. 
medios de ejercer la tutela administrativa (28). Da todos, el empleado aquí es el de la sustitución del ente tutelado, ya que la Comisión provincial actúa en lugar del Municipio interesado, como parte contratante de las obras de éste. También aborda este problema la pormenorizada Sentencia que glosamos En el tercer considerando, nos dice: "Que las obras reguladas en el Decreto de 1958, son obras netamente locales, sujetas a la competencia de las Administraciones locales, conforme a lo dispuesto en los artículos 101, 128, 143 y 287 de la Ley de Régimen locai, pero en su ejecución se ha interferido la Administración del Estado, recabando para sí y con una legitimación basada en la subvención económica de las obras, una competencia que oscurece y coloca en segundo plano, la competencia de los entes locales, pero sin que por ella desaparezca, como principio fundamental, la Administración provincial o municipal, como sujeto para quien se realiza la obran. De acuerdo con esta doctrina, creemos que puede $y$ ha de distinguirse entre competencia para cantratar la ejecución de las propias obras y el resto de las competencias implicadas por la titularidad de la obra que ha de realizarse. A la Comisión provincial de Servicios técnicos compete la realización de las obras y su contratación, y a la Administración municipal, la titularidad de la obra.

Por motivos de tutela, se altera la competencia de celebrar contratos de ejecución de obras públicas de las Corporaciones locales, no de una manera general, sino para el supuesto concreto que la Ley establece de obras subvencionadas a través de los planes provinciales de inversión. Aunque resulta obvio, es preciso aclarar que esta aịteración de competencia se opera por vía legal, concretamente a través de las disposiciones que regulan los tan repetidos planes provinciales de inversión, y que se produce en un momento anterior y completamente desligado del contrato que viene después, cuya naturaleza, como hemos dejado entrever, estimamos distinta en el supuesto en que la subasta sea

(28) Entrena Cuesta en el trabajo citado, página 129, ensaya una enumeración: de los medios de ejercer la tutela, aunque no con un carácter exhaustivo. 
adjudicada a un particular contratista o a la propia Administración municipal titular de la obra.

c) Aplicando rigurosamente el principio del concesionario o del contratista interpuesto, tendríamos que los Municipios no podrian realizar las obras que saca a subasta el Estádo, pero; aparte de 'que dicho principio ha quebrado profundamente en todos los campos, sea en ei de las obras públicas (29), sea en el del dominio público (30), sea en el del servicio público (31); ya en plena época liberal, como hace notar García de Enterría (32), los diferentes paises continentales, que se apoyan en un Derecho administrativo estatocéntrico, admitieron la posibilidad de que los Municipios pudiesen ser concesionarios de los servicios públicos de carácter industrial que, perteneciendo sú titularidad al Estado, afectaban a la propia ciudad. "Todo el cuidado en evitar -advierte Enterría- que la Administración realizase la actividad industrial en que consistía el montaje y prestación de estos servicios, que es a lo que responde el principio del concesionario preceptivamente interpuesto, falla en cuanto se admita precisamente que una Administración pueda ocupar la posición de concesionarion.

- Algo parecido a lo que analiza García de Enterría con respecto de los servicios públicos industriales, ocurre ahora con la realización de los proyectos de obras y servicios incluídos en los planes provinciales de inversión, cuando es adjudicada la subasta a las propias Corporaciones titulares de las expresadas obras y servicios. De este modo, se acentúa todavía más, en el campo de las obras públicas, la crisis del principio del concesionario o, mejor, del contratista interpuesto (33).

(29) Garcia de ENTERRta: Dos regulaciones orgánicas de la contratación ad. ministrativa, aRevista de Administración Pública», núm. 10.

(30) BALlé: Las reservas demaniales, aRevista de Administración Públicav nú. mero 4.

(31) GARcía DE ENTERRIA: La actividad industrial y mercantil de los $M u$. nicipios, aRevista de Administración Públicas, núm. 17.

(32) Op. cit., pág. 95.

(33) Este principio del concesionario o contratista interpuesto, fue consagrado por GARcía dE ENTERRfa en Dos regulaciones orgánicas..., pág. 251, y aceptada por GarRido Falia en su Tratado, volumen segundo, pág. 66. 
En el cuarto considerando de la Sentencia de la Sala de lo Contencioso-administrativo de la Audiencia de Barcelona de 9 de junio de 1961, se dice a este respecto: "que se desnaturaliza la fórmula del contrato y se violan los preceptos que regulan las fórmulas de realización de obras, en el Decreto de $\mathbf{1 3}$ de febrero de 1958 y Ley de 1 de julio de 1911, cuando bajo la categoría del contrato concertado a través de la subasta, queda la propia Administración titular de la obra y financiadora con el Estado de la misma, como verdadera ejecutora de aquélla, a través de una vía oblicua o indirecta, no pensada para esta finalidad, porque a través de la fórmula del contrato, pensada para encomendar la realización de la obra a un tercero, se ha logrado saltar por las prescripciones de la Ley y encomendar la ejecución de las obras a la propia Administración".

d) Con el contrato celebrado entre la Comisión provincial de Servicios técnicos y el Municipio, los Ayuntamientos no recuperan la competencia alterada por el Decreto de $\mathbf{1 3}$ de febrero de 1958 y demás disposiciones complementarias, ya que la competencia, aparte de ser irrenunciable, conforme al artículo $4 .^{\circ}$ de la Ley de Procedimiento administrativo, se agota con la celebración y subsiguiente cumplimiento del contrato, pero, en cambio, quedan facultados para la ejecución por sí de las obras, aun traicionando los fundamentos políticos del sistema.

En virtud de este contrato, si bien los Municipios pierden la competencia para contratar con un tercero interpuesto, siendo sustituídos por la Comisión provincial de Servicios técnicos, extienden sus facultades a la realización de obras, que, por lo general, no podrían realizar por sí, sino a través de un contratista particular. En definitiva, pues, estos contratos, si bien implican, en cuanto posibilidad, una centralización que viene postulada por la asunción, o al menos, la interferencia de una competencia municipa! - que se dará tanto en el caso en que la subasta sea adjudicada a un Ayuntamiento como a un contratista-, suponen, en cuanto efectividad, una potenciación de la actividad municipal. Tanto el aspecto centralizador, como el que se refiere a la extensión de las faculrades del Municipio, respon- 
den a una misma finalidad: la eficacia de la Administración. De un lado, a través del planeamiento de las obras y servicios en los múltiples núcleos urbanos de la Provincia, se realizan aquéllos en forma incomparablemente más eficiente, ya que responden a una visión colectiva y no casuística (34). De otro, al permitir a los Ayuntamientos que ejecuten por sí las propias obras, hacen posible, en muchos aspectos, la construcción de unas obras o la instalación de unos servicios, que, de otra forma, en la gran cantidad de Municipios pobres que se extienden por la geografía española, tardarían muchos años en llevarse a cabo. Basta recordar que el Municipio que interpuso recurso contra la liquidación de la Abogacía del Estado que dio lugar a la Sentencia glosada en este último apartado, efectuó, como tantos otros, la aportación municipal correspondiente, no en metálico -cosa imposible-, sino arbitrando el medio financiero de las prestaciones personales obligatorias y voluntarias (35). Como es natural, esta extraña, pero única posible aportación municipal, ahuyentó a los contratistas privados. Por ello, tuvo que adjudicarse la subasta al Ayuntamiento interesado, único postor.

En vista de estas circunstancias de hecho, hubiese sido injusto aceptar la tesis de la Abogacía del Estado, que venía a detraer una cantidad imposible del esquilmado erario municipal.

Ha de recibirse con alborozo, por tanto, la Sentencia glosada, una de las primeras de nuestras flamantes Salas de lo Contencioso-administrativo, que tan justamente ha venido a saltar sobre los formalismos y las apariencias para detenerse en la relación de vida subyacente, acompañando, además, sus argumentaciones, de un rigor y ura técnica jurídico-administrativa envidiables.

(34) Gnrcfa de Enterrfa: alla Provincia en el Régimen local españoln, incluida en Problemas actuales de Régimen local, pág. 33.

(35) Es fundamental en cuanto a las prestaciones obligatorias, la obra de LUCIFREDI: Le prestazioni obligatorie in natura dei privati alle pubbliche Amministrazioni, Padova, 1034. Con respecto a las prestaciones voluntarias, se trata de una figura ra:amente encontrable en los tratados de Derecho administrativo, pero en el texto demostramos su realidad, por lo que seria interesante estudiar el prob'ema de su naturaleza juridica. Para nosotros no se trata más que de un contrato administrativo, atendida la fina.idad que con el mismo se persigue. 